\title{
Chapter 3 \\ Becoming World Class: What It Means and What It Does
}

\author{
Mats Benner
}

\begin{abstract}
On the basis of a critical survey of university strategies, it is argued that universities reify and objectify "world class" and turn it into absolute and precisely defined goals (location in ranking hierarchies, publication patterns, number of startups and licens-es, etc.) and that this in turn is based on a skewed reading of the ascendancy of some universities (notably leading US higher education institutions) to that level. The notion of a "world class university" may therefore be self-defeating as it entails even closer monitoring, adaptation and adoption of indicators and steering that is outlined accordingly.
\end{abstract}

\section{Introduction}

"World class" has become a central goal in university policy worldwide. The concept in turn is dependent on the emergence of measurements and yardsticks of "world class" and how it might be attained. University rankings form a key part in the construction of "world class" as a measurable and purportedly attainable goal for universities - and the construction of an organizational identity as "ranked" and "measured". This paper affords an analysis of how one instrument in the constitution of "world class", university rankings, influences university governance. In particular, the focus is on how universities of different composition and historical roles have - and could — relate to rankings and other proxies of "world class".

M. Benner $(\square)$

Professor of Science Policy Studies at Lund University School of Economics and

Management, Lund, Sweden

e-mail: mats.benner@fek.lu.se

S. Rider et al. (eds.), World Class Universities, Evaluating Education:

Normative Systems and Institutional Practices,

https://doi.org/10.1007/978-981-15-7598-3_3 


\section{Measuring Universities-A Historical Sketch}

Who's afraid of world class universities these days? No one it seems. China's Double First Class Plan from 2015 was set up to propel 42 universities and 185 disciplines into leading international standard, aiming to make China a globally dominant "higher education power" by 2050. Japan's Top Global University Project (from 2014) took as its goal to make 13 universities part of the top 100 universities in the world. India's government, which has been reluctant to accept the rather dismal positions of Indian universities in global rankings, has recently launched an initiative to designate six universities "Institutions of Eminence", with degrees of freedom and resource allocation far surpassing those of ordinary higher education institutions in the country (Benner, forthcoming). Europe has had its share of world class initiatives as well. The German excellence initiative is one of the most profiled initiatives on the continent, France has in waves initiated schemes to propel its universities to the global top rank. In 2009, then President Sarkozy stated: "Our aim is quite simple: we want the best universities in the world." (cited in The Guardian, December 142,009). The European Union at first eschewed and criticized global rankings, and instead supported the development of U-Multirank as an alternative allowing "users to develop their own personalised rankings by selecting indicators in terms of their own preferences" (https://www.umultirank.org/about/u-multirank/ the-project/). However, more recently, the European Union has championed the notion of "networks of universities" (initially launched by France's President Macron), helping European universities to boost their academic performance and the mobility of students and faculty, with the following motive: "The consensus is that European universities are not competitive on a global level-even the best we have are far behind ones in Asia and the US" (Kelly 2018).

Hence, the notion of a global hierarchy of universities - with world class as denominator of a top position within that hierarchy-has taken hold of university policy. The pattern is not valid everywhere, it should be noted. The two main exceptions are Africa and Latin America, where pressing concerns-social cleavages and historical legacies chief among them-have made their structure and work modes less compatible with the definitions of "world class" (Hazelkorn 2012). But with those two notable exceptions, "world class", despite its fluidity, has emerged as a yardstick for university policies in many countries. But what does world class mean? And how is that meaning transformed into action within universities?

\section{World Class: Theoretical Foundations and Implications}

In this paper, I will argue that rankings function as a critical intermediary between global trends on the one hand, and university activity on the other hand. A global university system, and ensuing notions of world class, are shaped by comparative instruments, with rankings emerging as stratifying devices. Rankings also function 
as devices which in themselves create and reproduce notions of what qualities in universities are and which instigate strategic re-considerations within universities.

The underlying assumption of this paper is that rankings are part of the emergence of measurements and hierarchizations of heterogeneous entities, driven by factors that both allow for standardization and match articulated needs to standardize. Any kind of organizational structure, from voluntary associations to nationstates, builds on standardized measures for inclusion and exclusion (Ahrne 1994). This organizational quality in turn has allowed for the standardization of such organized activities, including comparisons and measurements, a standardization that is embedded in processes of vertical management control. Organizations tend also to be closed to one another, even if they operate in similar areas, to ensure secrecy and to elevate organizational dominance over members and employees (Costas and Grey 2016). However, universities have traditionally been viewed and understood as loose confederations of activities and people, with few uniting elements and relatively diffuse organizational hierarchy within them —or for that matter clear-cut barriers between them and the external world (Clark 1983). Taken together, this would make comparisons and rankings meaningless, as the boundaries between universities as well as their internal relations, are too vague to pinpoint what is actually being measured and compared.

Nonetheless, several processes have, arguably, reduced the fuzziness (and ensuing incomparability) of universities. An organizational structure has emerged as a global template of efficiency and accountability, affecting also areas and activities that have been impossible or difficult to square with such structures. Rankings have also evolved in productive parallel with the rise of a world order of science, affecting how societies are governed (and by whom), but also leading to an increased homogenization on a global scale of the processes and organizational forms of science (Drori et al. 2003). Rankings thus emerge as part of an instrument to measure and compare activities that increasingly share properties, which has, unsurprisingly, fostered a rise of managerial techniques to control behavior and relations within universities, with rankings serving as a foundation for such managerial ambitions (Huzzard et al. 2017). Rankings may thus provide an impetus for universities to disentangle and describe their actions, but they may equally well contribute to a homogenization of practices and disregard of specific conditions pertaining to their location, history and financial underpinnings (Muller 2018).

The outcome of this, I assume, is an unstable combination of global templates and local practices, forged by combinations of imitation and the enmeshing of global and national (or local) practices (Fourcade 2009; Wedlin 2006). While universities are increasingly exposed to global comparisons, and indeed voluntarily expose themselves to such hierarchical exercises, their approach to such comparisons can be expected to vary according to their historical role and missions, resource base, task structure and their form of patronage (Thoening and Paradeise 2016). We should therefore distinguish between different types of universities and how they might approach and deploy rankings and other structuring devices. Such distinctions, which we will turn to later on in this chapter, should reflect the aforementioned factors: 
- Historical role

- Missions

- Resource base

- Task structure

- Patronage

To sum up, I assume that rankings and notions of world class have become globally dispersed and disseminated, and enmeshed in university practices, and their organizational structure and internal relations. However, I also assume that the uptake will vary depending the organizational properties of universities. This leads us to the issue of what rankings are, how they have evolved, how they are structured, before we venture onto the issue of how world class is understood and acted upon by different types of universities.

\section{Can Universities be Compared?}

Universities, while truly international as organizations (in their professional nomenclature and their disciplinary structure), have historically been closely tied to national conditions and national concerns, with only limited opportunities to compare beyond (and often also within) national boundaries. Indeed, most comparative studies of universities have emphasized the systemic difference between universities in different national settings (Clark 1983).

Their funding and their tasks have been at the same time detailed and loose. Governments or other patrons regulated the administrative procedures for universities and gave broad remits for their missions in education and research. Within this broad framework, universities enjoyed considerable operational autonomy (Clark 1983). Hence, universities have operated in a concomitantly national, political and autonomous space. While there were certainly sharp demarcations within the group of universities - with differences in funding and reputation to match-these demarcations were seldom or never translated into lists or explicit hierarchies, neither domestically or internationally. Following Clark's typology, universities were either market-oriented, politically-oriented, or academically-oriented in their governance. Market-oriented universities - exemplified by the USA - were determined by competitive forces, either in the form of pecuniary resources (the recruitment of fee paying students, the mobilization of external support for research in competitive processes), and operated in an organizational ecology with competition-based (and therefore variable) positions. A typical such hierarchization is afforded by Hermanowicz (2010), who distinguishes between elite universities, pluralist universities, and community colleges. Elite universities (leading private universities such as Harvard and Stanford, plus a select number of "flagship" public universities such as Berkeley and Michigan) are marked by international recruitment of students and staff, large numbers of faculty being members of learned societies, prominent prizewinners, prestigious funding, and so on. Pluralist universities-typically state 
universities with more limited research budgets—are primarily defined by their educational remit and broad recruitment profile, and have neither the resources nor the mandate to pursue activities that aim for the prestige of the top-tier universities. Community colleges in turn provide essentially societal services and engage only occasionally in research. This stable hierarchy was, albeit unintentionally, the template for ranking policies, namely, to concentrate resources and prestige to a small set of institutions while giving the rest of the higher education landscape more constricted and confined roles.

For universities in politically governed academic systems-Sweden is the example chosen by Clark - the overarching determining role is that of a prolongation of politically decided functions and governance mechanisms. Universities are primarily seen as extensions of political power, and are shaped and moulded by such expectations. They operate in a hierarchical system, though, as political steering is blended with historical appropriations and task assignment to the universities, with marked differences between old comprehensive universities, new comprehensive universities, old specialized universities and more recent specialized ones. But the ambition has not been to elevate a small set of institutions to a position of excessive privileges, but rather to mitigate the preexisting hierarchies by emphasizing missions and mandates rather than preselected institutional positions.

For the third category of university systems identified by Clark, those primarily governed by intrinsic academic procedures and values, hierarchies and positions are not tied to institutions but to professional roles. This gives the professoriate a dominant role in the procedures of academic environments. While this is not in itself incompatible with the accumulation of prestige in some higher education institutions, the direction of higher education policy is not to create a select number of high-ranking institutions. Instead, countries marked by "academic oligarchies" (Clark's term) operate on a sharp bifurcation, where universities are either part of a rather homogeneous group of venerable institutions or part of a set of practiceoriented sites, with only limited status differentials within those groups. Belgium or the Netherlands are clear examples of this, where a set of universities has been deemed more or less equally well-performing without any major differentials in funding or governance arrangements-or specific initiatives takes to elevate their respective positions.

Clark depicted the university systems in operation after WW2 until the 1980swith some elements remaining even today. What has happened since has been a partial convergence, in the sense that the capacity of the US university system to produce high impact research, scientific prizes and globally leading institutions, has become a policy template for others to emulate (Aghion et al. 2010; Marginson 2009). While the recipe for how to emulate the US exemplar varies, and the recipe itself is not widely known even in the US (Cole 2010; Labaree 2017), the notion of "world class" and "excellent" universities has spread, as has the notion of "entrepreneurial universities", that is, universities that have developed governance models for evaluating them out of dependence on the state and instead engage with markets and other non-public stakeholders. For the Nordic countries, the last couple of decades have seen the rise of new ways of governing universities, with increasing 
organizational leeway, performance-based funding and enforced mergers and reorganizations (Pinheiro and Geschwind 2018). While little of this has been explicitly based on ranking positions and the like-indeed, in some cases (notably in Norway), the effect has been the opposite, namely, to decrease the ranking positions of universities that have been merged (Bjørgan 2018) - the reforms reflect a globalized template of university governance. For the US, the last decades have seen continuity rather than change as the North American universities still constitute the very template for many of the rankings available. This notwithstanding, even they are in the midst of various mutations and reforms, notably, to ensure that their contribution to societal development are properly organized, so as to ensure affordability and alignment with critical issues for US society (Christensen and Eyring 2011; Crow and Dabars 2018).

The most significant change in recent history is, of course, the rise of Asia within global higher education and research (Benner, forthcoming). The main instruments for the elevation of Asian universities in the aforementioned countries have been resource mobilization and the recruitment of students and staff from the region. But a significant measure to bolster and direct activity has been the use of rankings. University rankings are used explicitly in university governance in some Asian countries, and influence recruitment policies, resource allocation and organizational strategies, certainly not as the sole input, but as one of several measures to assess achievements of individual universities, but also of the nation as a whole (these countries typically aim to have a certain number of higher education institutions within the global 100 or 200 universities). In addition, rankings have been elevated as a side-effect of the global mobility of Asian - in particular, Chinese - students, who use rankings as a selection device in their search for locations of their international studies (Chao et al. 2017).

The outcome has been the continuous proliferation of ways to enable comparisons but also yardsticks for university performance. Indeed, the very notion of "performance" has been established only rather recently, and rankings have been instrumental in this process. While both the theoretical and methodological foundations of this development are rudimentary, much of the literature on higher education institutions pointing at the increasing complexity of universities qua organizations, the practice of performance measurement and organizational comparisons has been undeterred. This situation reflects in part the globalizing nature of university environments, marked by student and staff mobility, and the mounting interactivity in communication and in collaboration which compels universities and university systems to relate to their environments, scan and map them so as to act on the basis of that information. This translational process has been largely driven by actors and interests that operate outside the confines and control of the higher education institutions themselves. We would therefore expect both a reflective deployment of rankings as well as a critical discussion of the value of the information they provide and how that information might feed into the governance of universities. 


\section{Rankings and their Methodologies}

As mentioned, rankings are a relatively recent phenomenon in university governance and politics. Starting out as a media-based attempt (emanating in the US and then spread to Europe) to assess and evaluate which universities are by one measure or another deemed "best" in a national context, they have developed into a global template for measuring and comparing universities. The most important element in this surge of rankings was the Shanghai ranking (officially Academic Ranking of World Universities, ARWU) commenced in 2003, which set out to disentangle different groups or strata of universities globally. The Shanghai formula is not hegemonic, but has rather been complemented by a different model, spearheaded by the Times Higher Education Supplement's ranking, now split into two, QS and THES, with some commonalities but also some fundamental differences.

ARWU is often considered the most influential of all contemporary university rankings (Marginson 2014; cf. Fernández-Cano et al. 2018). Developed to serve as a yardstick for the renovation of China's elite universities, it has evolved into a powerful instrument to compare and assess the qualities of the world's universities. It is based on six indicators that are assumed to measure the degree of institutional excellence:

- Quality of alumni: the number of alumni that have received the highest scientific awards (Nobel prizes, Fields prize)

- Quality of teaching: the number of teachers who have received Nobel and Fields prizes

- Quality of staff: the number of staff belonging to the category of "highly cited researchers" in 21 different fields

- Quality of research: the number of papers in Nature and Science (with special reference to first or corresponding authorship)

- Quality of research: the number of papers in journals indexed in the Science Citation Index and the Social Science Citation Index

- Productivity: as measured in the number of publications per full-time faculty members.

The first and last of these indicators represent $10 \%$ of the total weight of the ranking, the other four $20 \%$ each.

The Shanghai ranking is based on an ideal university, the research-focused, large-scale (comprehensive, almost by necessity including a medical school), resource-intensive university that operates in a global system of recruitment, retention and reward. This, again, reflects the duality of the Shanghai ranking: it is based on the contemporary conception of a "world class university", namely, one which hosts scholars who are leading in their respective fields, at the topmost level (Nobel prizes, etc.), and at the next highest level (highly cited) and which have at its disposal instruments to assure that productivity is high and widespread.

Another ranking exercise that has been described as the most transparent and the least marred with methodological ambiguities (Fernández-Cano et al. 2018), is the 
Leiden ranking, based solely on bibliometrics, with data provided by the Web of Science database (Clarivate Analytics). It has been continuously refined since it was launched in 2003, and is updated annually. In its most recent incarnation, it covers the period 2013-2016, and papers published in English and in so-called core journals (with an international, rather than purely national, reach and remit). It covers around 1000 universities worldwide: the smallest one produces 1000 publications over a four-year period (Rockefeller University), the largest one (Harvard University) 30 times more. Incidentally, they are number 1 and number 4, respectively, in terms of scientific impact at the highest level (1\%).

The Leiden ranking uses two measures to rank universities: scientific impact and collaboration. Scientific impact is ranked at different levels of refinement, from $1 \%$ (as proportion of publications that belong to the one 1\% most cited) to $50 \%$ (Fernández-Cano et al. 2018). This gives an indication of how influential a given university is in the production of the most influential publications ( $1 \%$ being a very small set, $10 \%$ a reasonably large one, and 50\% indicating the breadth of publications and its relation to the world average). In addition, the Leiden ranking provides information on the mean number of citations of a given publication from a given university.

The Leiden ranking profiles itself as a transparent and reflexive ranking, transparent in that it only uses publicly available data, reflexive, in so far as it includes critical reflection on the very exercise of ranking universities and deploying the data available. It has also cautioned against the use of rankings more generally (Waltman, Wouters, and van Eck 2017).

Moving then to the other ideal type, which draws heavily on the inclusion of peer review, are the QS ranking and the Times Higher Education World University Rankings (THE), respectively. These rankings typically profile a mixed set of indicators, organized into four broad categories: teaching environment, research volume and impact, international reputation, and collaboration with industry. These rankings are therefore more complex and thus target slightly broader audiences than the ARWU ranking.

QS and THE afford a degree of openness and reflexivity concerning their methodological considerations, pitfalls and opportunities. ${ }^{1}$ A critical element for them is comparability between disciplines and areas of specialization for research performance, response rates among academics in the peer review, or the balance between national and international reputation.

They structure these inputs somewhat differently: THE gives $30 \%$ weight to the teaching environment, $60 \%$ to research (of which $30 \%$ is based on bibliometrical measures), and the remaining $10 \%$ to international reputation (7.5\%) and collaboration with industry (2.5\%).

Reputation surveys have a strong influence on these rankings. For THE, the teaching component represents half of the ranking value. Research represents $60 \%$ of the total value. QS operates with slightly different weightings. It does not include

\footnotetext{
${ }^{1}$ http://www.iu.qs.com/university-rankings/subject-tables/
} 
financial metrics, but instead puts an even heavier emphasis on peer surveys (40\% in the world university ranking, with more than 80,000 respondents altogether). It further gives a 10\% weighting to responses in an employers' survey (40,000 respondents). It follows THE in including a citation analysis (citations per faculty, with weighting according to research areas, which accounts for 20\%), faculty/student ratio (20\%), and international faculty/international student ratio (10\%).

QS and THE have been somewhat less influential as global yardsticks compared with the Shanghai ranking, but they are intended to be more versatile and flexible (Marginson 2017). They have also taken on a somewhat different strategic orientation than Shanghai, with various extra and sub-rankings tailored to different consumers, such as for newer universities, or targeting specific disciplines and areas. This reflects their foundation on the market value of rankings, and the ability of their patrons to secure increased revenue for ranking exercises. Their methodologies rely heavily on their peer review approach, which-albeit corrected to reflect the composition of responses-reproduce conceptions of a reputational hierarchy heavily skewed towards Anglo-Saxon universities.

In conclusion, rankings are based on a fundamental theoretical and methodological challenge, namely, to pare down a very complex set of activities into a small number of indicators, which are in turn conjoined. They also struggle with the relatively complicated matter of data management and the desire to manipulate and change weightings and relative importance over time with expectations of predictability and longevity. This, as we shall see, is in turn a reflection of the rather abrupt introduction of rankings as a measure of both communication strategies among universities. The fact that rankings have grown in importance as a source of identity and instrument for internal steering (and, to some extent, government policy) has increased the pressure on the rankings to be refined and changed intermittently.

One of the main weaknesses of rankings is the limited intersubjectivity, as ranking position tends to be different depending on the ranking at hand. Lund University ranks among the top 100 in QS and UWR, in the 101-150 category in ARWU, and as 353 in Leiden. While some of this variation is inevitable, it also invites an à la carte approach to rankings, as they may vary significantly and no stable standard exists. This has also led to the introduction of very heterogeneous and inclusive rankings — not included in this report—such as the multi-rank exercise, which offers rankings that may satisfy needs and interests of those institutions that do not necessarily score very highly in other rankings. There has also been a surge of more or less dubious rankings which elevate specific experiences at the expense of others (Donetskaia 2017). Multi-rank, the European Union's alternative measure, merely underlines this tendency, as its multidimensional form-intended to serve as a complement to the skewed focus of existing rankings-primarily reflects another university ideal.

The different rankings therefore represent different forms of predefined yardsticks of world class: ARWU favours the North American large-scale researchintensive university ideal, whereas QS and THE favor Anglo-Saxon universities more generally (Bornmann and Glänzel 2017). While this reflects tendencies in how universities globally are oriented and where they identify strategic directions 
(Marginson 2008), it nevertheless indicates a defining weakness among rankings, namely, that they reproduce current understandings of university qualities rather than emerging ones. If rankings are to be sustained, they need to find measures that encourage innovation and change, not only adaptations to global best practices.

\section{Different Types of Universities, Different Responses}

A key element in the understanding of what rankings are concerns how they are met with, and acted upon, by universities. It has generally been assumed that rankings are an increasingly important backdrop to university strategy (Hazelkorn 2007, 2008). However, as has been argued above, the role of rankings and other measures of "world class" may vary between different types of universities. Thoening and Paradeise (2016) have identified four types of universities, and this typology can be modified according to how the types approach and deploy rankings:

- One category is the "top of the pile university", recognized as globally leading higher education institutions (e.g. Harvard)

- Another category is "venerables", with a solid national position but less pronounced international visibility (e.g. Uppsala)

- A third category captures the "wannabes", universities with only limited international recognition but with the explicit aim of enhancing their international status and visibility (e.g. National University of Singapore)

- A fourth category encompasses relatively small, applied and new ("missionary") universities, with missions tied to local rather than global conditions (e.g. Jönköping University).

Top of the pile universities belong the leading 20-30 universities in the world. They generally have large budgets, especially for research, compiled through a combination of state appropriations and competition-based funding, and/or with significant amounts of accumulated capital, land ownings or endowments. In their academic work, they aim for disruptive and innovative activities, and to match those ambitions recruitment of faculty tends to be global and recurrent; they consider themselves "recruitment machines" more than anything else. Strategic thinking among these universities is generally long-term, aiming to secure and possibly propel their status in relation to other leading institutions. Strategies in these universities tend to evolve from both the top level and from the level of faculty-i.e. university-wide leadership sets goals with regard to research incomes, participating in certain selective fora, and the formation of networks and activities that are conducive to the goal of being "truly world class". Their main yardstick is therefore international, and they aim not only for international recruitment of students, but also to attract faculty and funding globally.

How do these universities relate to rankings and other measures of "world class"? One might expect them to disregard such notions, but the contrary can be argued. Rankings may confirm their position as institutions that outsize their national role, 
i.e. they not only serve as leading institutions in their own university system but also function as nodes in a global system. Rankings give their patrons evidence of their performance, but they also serve as yardsticks to elevate ambition, reduce internal slack and generally exert productive pressure as well as reproduce conducive modes of operation and generalize a quality culture and quality norms. With internal expectations of strong management, the leadership needs underpinnings: rankings may serve as one input for those ambitions. Rankings are primarily aimed at ensuring that no major reputation drop is recorded, and that the university is in good company: top of the pile, indicating that it belongs to a group of universities that define quality and impact. This also means, perhaps somewhat paradoxically, that these universities are less critical of the methodologies of rankings than the venerables; given that they aim for the highest positions in the rankings, they adhere and adapt to the principles of the rankings.

We have studied one of the universities in this category. For it, rankings are used among other criteria of a "leading" university: its top performance in employability, its global links, its location, its linkages and its position in global rankings conjoin to give the university its identity. In this case, the identity work has also laid ground for some radical redeployments of resources, including significant cuts in one of its faculties and the parallel inauguration of a business school as well as the construction of new buildings. In this process, rankings served as one of many inputs, in particular regarding international attractiveness and how that might be attained. When a new Vice Chancellor was appointed, a numerical goal was set to belong to the "super-elite" group of universities in the top 20 of the world (cf. Hertig 2016).

A second category deployed by Thoenig and Paradeise (2016) is that of venerables. These universities have a stable position in their national contexts, as leading or among the leading with respect to reputation and attractiveness, but their international visibility is less pronounced than the top of the pile universities. Typically, they would count as among the global 100-200 universities, reputable but without the position (or funding) that ensues with the elite status.

For these universities, appropriations are more modest than for the leading universities, and predominantly based on student number, historical trajectories, with some additional funding available for various profiling purposes (typically centers of excellence or collaboration with industry). These universities tend therefore to focus on the constraints rather than the opportunities associated with their position in the national university policy system but also internationally: "we will never be widely known internationally", said one vice chancellor of a venerable institution, as an indication of the (relatively) limited reach of rankings. Nevertheless, this university, like others in this category, keeps track of its performance and from time to time compares itself with equivalent institutions, both nationally and internationally. This approach is similar to the tracking within a field of similar universities but in adjacent systems that the top of the pile institutions do. On the basis of this, the university at hand argues that it has had a much stronger development as a research university in terms of scientific impact and scientific prizes than other similar-sized universities. In fact, and this is pointed out in the interview, it has actually taken some measures to profile its international reputation (recently its position in the 
THES ranking) as a vehicle in discussions with the relevant ministry. In addition to such ad-hoc measures and activities, it does not consider itself very active in relation to rankings as its position is more difficult to translate into specific actions than it is for the "super-elite", where both financial, recruitment, and visibility goals are more tangible. Hence, this and other venerables are neither very high profiled nor entirely disengaged.

Like the top of the pile universities, these universities view THES and QS as the most relevant of the global rankings available-contrary to the popular belief (also in Marginson 2014) that ARWU matters the most. For universities with only few or no historical or active Nobel or Fields prize winners, ARWU is seen as too geared to extreme measures of excellence, whereas THES and QS are more versatile and flexible. They are viewed as valid even though the methodology, especially the dynamic view of weightings, is questioned, as is the lack of transparency. They also find the competition for services and arrangements surrounding rankings, including some of the top of the pile institutions, cumbersome, and they find it difficult to understand why some universities are so actively engaged.

The official standpoint among venerables tends to be that recruitments and resource deployment are not contingent upon rankings. However, it was observed in one interview that internationally recruited faculty benefit from rankings as they help them identify the institutional status of the university. Students at this type of institution tend to be less inclined to engage in ranking exercises, as they fear that it might drive the orientation too much towards research priorities and recruitment exercises internationally, to the detriment of current student conditions. The differences with top of the pile institutions should not be exaggerated, not least because of the small data set on which these observations are made, but rankings must align with their constrained resources, dependence on the state and their recruitment profile, which is still largely national. Unlike the top of the pile universities, for which the rankings serve as an important yardstick, the venerables studied here seem to fear that their fragile balance between different interests and goals are rocked if rankings are taken "too seriously": they express the anxiety of rankings becoming straitjackets, and instead wish for them to measure comparable issues but not point universities in specific strategic directions that are currently not attainable for them. This ties in with the generally rather constrained strategic maneuvering space of these universities: they strive to reduce complexity and risks, in contrast to the top of the pile universities which aim to maximize their exposure to change and innovation. Hence, rankings may serve as a disturbing force for the venerables; by keeping rankings at arm's length, however, they run the risk of stagnation and an overly strong focus on stability and incremental change.

A third category, applicable to the Asian experience (Benner, forthcoming), is that of wannabe universities. These universities challenge the venerables in particular by actually aiming to be counted among the leading universities in the world, if perhaps not (yet) as part of the "super elite" which still are far more influential. Wannabe universities share with the venerables the relatively modest international status, but they match this with a totally different type of engagement both from their patrons-normally the state-and from within the universities. Wannabe 
universities are embedded in national strategies to raise resources to attract students and staff, both nationally and internationally (in particular from other Asian countries, but also to some extent from North America and Europe). Governments invest heavily in these universities, in particular for research, and align these expectations with various numerical goals, rankings chief among these. For the wannabe universities, ARWU seems to have a better alignment than QS or THE, as the former points in the direction of goals that are embraced by their patron governments, such as high impact papers, contributions to Nature and Science, and globally leading scientific prizes. They do not aim to the same degree for the rounded profile that QS and THE reward, and may be seen largely as emulating the North American ideal of the research-intensive and resource-intensive institutions that climb the ladder of international recognition via massive infusions of resources and recruitments into fast-moving areas. Their time-horizon is also quite short: the strategies of these universities tend to focus on and reward short-term and tangible gains in rewards and recognition, and rankings tend therefore to be of considerable importance as they give recurrent feedback on the development of specific fields and specific institutions. Ranking positions tend therefore to be included in the dialogue between patrons and universities. For these universities, top-down steering via managerial prerogative is an immanent feature, and rankings therefore deployed as an instrument to steer and evaluate not only on a general level, but also in some detail. If the top of the pile universities use rankings as a device to ensure that they are still defining the frontiers of their respective activities, and venerables use various techniques to ensure that rankings do not cause internal friction or radical changes in university governance, rankings function as yardsticks and measures of progress for the wannabe universities. Rankings identify, in a rather pedantic and straightforward manner, a set of institutional models and measures that can be deployed to reach the desired status. These are then in turn implemented through the organizations and applied systematically to recruitments and rewards (Benner, forthcoming).

The final category, missionary universities, represent the broad range of universities that operate with only marginal alignment with rankings, either because of their profiles (they are often single faculty universities) or due to their age and reputation (which are nascent). Simply put, their profiles and historical legacy are neither rewarded nor recognized in rankings. Among these universities we may discern different strategies, but most of them seem to deploy a strategy of being an actively unranked university, viewing rankings as largely unproductive; for them, the main matter is comparability and justice (in the sense that indicators should be dynamic and not simply punish newcomers). The missionary universities thus operate through the identification of specific profile areas, where they want to align innovative research profiles with educational and social engagement and collaboration. Instead of aiming to reinvent and innovate entire fields, or to ensure that their reputations are at an international level (whatever that is taken to mean), the missionary universities seek alliances with governments and other patrons who support and reward specific profiles. They share this trait with the wannabe universities, which aim to excel in particular fields where they can enhance their international standing (and align that with national goals). For the missionaries, the goals are somewhat 
more eclectic, as they primarily seek to forge alliances with local interests, with more modest aims to excel in fast-growing globalized fields. If a national system of negotiated profiles in which historical factors were downplayed were to be established, the universities could leverage their status on the basis of such profiles. This would also enable them to translate their active non-engagement with rankings into clear-cut internal strategies of priority-setting and profiling. Without such alliances and such yardsticks of progress and success, they are left without direction.

\section{Conclusions: Will World Class Prevail?}

Rankings, despite their multifaceted origins, have morphed into a governance force to structure and hierarchize universities in the world. Rankings are by definitions intended to produce lists, and in so doing they represent a sharp break with one of the foundations of both higher education policy and studies of higher education institutions, namely that universities are embedded in their settings and contexts. They reflect the existing hierarchies and the steady state of higher education institutions-based on language, size, research income and other factors that are not universally distributed. While this has been alleviated by some measures (such as rankings of institutions below the age of 50), rankings tend to reward and highlight institutions that are already widely known and recognized. Rankings are therefore somewhat of a self-defeating game, as rankings reproduce existing hierarchies among universities, in particular between categories of higher education institutions: globally leading ("top of the pile") universities, "venerable" universities (say, top 100), "wannabe universities" (relatively low-ranking institutions moving in an upward direction) and an undifferentiated group of "missionary" universities with limited capacity (or willingness) to climb in the ranking tables.

Despite multiple methodological drawbacks, a shallow theoretical foundation, and commercial alignments and implications, rankings are instruments utilized for institutional capacity-building and university strategy. One reason for this is that rankings provide benchmarks for universities and identify certain properties associated with different ranking positions. Rankings, along with many other data sources available, are used by universities for a variety of purposes. They are rarely used directly (e.g. for recruitments and the like) in "mature" higher education systems, but more often so in emerging higher education systems where recruitments tend to be based on citation patterns, prizes and similar indicators. They have, in addition, become one of many outcome instruments available to higher education policy in its totality: from students to policymakers, rankings are seen as indicators of relative positions in a (partially) global higher education system according to a (delimited) set of objectives for higher education. They are also deployed to some extent by the higher education institutions as steering instruments in their profiling, external communication and internal processes.

The implications for universities vary. For globally leading (top of the pile) universities, as well as wannabe universities, rankings are of rather great significance. 
For mid-range (venerable) universities with secure national identities and roles but variegated conditions in global comparison, they matter less. Rankings may instead pose a challenge for the rather loose organizational and leadership structure of these universities. However, somewhat paradoxically, the venerables profile their ranking positions externally and are therefore rather vulnerable. They are therefore the type of universities that are most affected by the rankings. As a result, some of the venerables have taken on a more active relationship to the rankings, for instance by hiring analysts and integrating ranking as one (of many) ingredients in their strategy work. Are notions of "world class" therefore irrelevant and useless? Unsurprisingly, they do not come across as panaceas, even for the more ardent followers, but as one of many different reference points for a university that claims to be among the leading universities in the world. The alternative would of course be to avoid such comparisons and such unstable claims (unstable in the sense that they may change, and that they do not reflect any objective measures or analyses). That, on the other hand, would entail a very different approach to external communication and perhaps also an activist stance among universities in the world towards the phenomenon of rankings and comparison altogether.

\section{References}

Aghion, P., et al. (2010). The governance and performance of universities: Evidence from Europe and the US. Economic Policy, 25(61), 7-59.

Ahrne, G. (1994). Social organizations. London: SAGE.

Benner, M. (Forthcoming). The rise of Asian universities: Miracle or mirage? Ms.

Bjørgan, E. H. (2018, September 27). NTNU faller 100 plasser på ny rangering. UA. Retrieved from https://www.universitetsavisa.no/nyheter/2018/09/27/NTNU-faller-100-plasser-på-nyrangering-18364582.ece.

Bornmann, L., \& Glänzel, W. (2017). Applying the CSS method to bibliometric indicators used in (university) rankings. Scientometrics, 110(2), 1077-1079.

Chao, C., et al. (2017). Chinese students' motivations for studying in the United States. Journal of International Students, 7(2), 257-269.

Christensen, C. M., \& Eyring, H. J. (2011). The innovative university: Changing the DNA of higher education from the inside out. Cambridge, MA: Harvard Business School Press.

Clark, B. R. (1983). The higher education system: Academic Organization in Cross-National Perspective. Berkeley: University of California Press.

Cole, J. (2010). The great American University. New York: PublicAffairs.

Costas, J., \& Grey, C. (2016). Secrecy at work. The hidden architecture of organizational life. Redwood City: Stanford University Press.

Crow, M. M., \& Dabars, W. B. (2018). Designing the new American University. Baltimore: Johns Hopkins University Press.

Donetskaia, S. S. (2017). The Berlin principles in Russian university rankings. Problems of Economic Transition, 59(7-9), 614-626.

Drori, G. S., et al. (2003). Science in the modern world polity. Institutionalization and globalization. Stanford: Stanford University Press.

Fernández-Cano, A., et al. (2018). Questioning the Shanghai ranking methodology as a tool for the evaluation of universities: An integrative review. Scientometrics, 116(3), 2069-2083. 
Fourcade, M. (2009). Economists and societies: Discipline and profession in the United States, Britain, \& France, 1890s to 1990s. Princeton: Princeton University Press.

Hazelkorn, E. (2007). The impact of league tables and ranking systems on higher education decision making. Higher Education Management and Policy, 19(2), 87-155.

Hazelkorn, E. (2008). Rankings and the battle for world-class excellence: Institutional strategies and policy choices. Higher Education Management and Policy, 21(1), 1-22.

Hazelkorn, E. (2012). Reflections on a decade of global rankings: What we've learned and outstanding issues. European Journal of Education, 49(1), 12-28.

Hermanowicz, J. C. (2010). Lives in science. How institutions affect academic careers. Chicago: University of Chicago Press.

Hertig, H. P. (2016). Universities, rankings and the dynamics of global higher education. Berlin: Springer.

Huzzard, T., Benner, M., \& Kärreman, D. (2017). The corporatization of the business school: Minerva meets the market. London: Routledge.

Kelly, E. (2018, October 25). EU launches $€ 30 \mathrm{M}$ pilot scheme to create networks of European Universities. ScienceBusiness. Retrieved from https://sciencebusiness.net/news/ eu-launches-eu30m-pilot-scheme-create-networks-european-universities.

Labaree, D. F. (2017). A perfect mess: The unlikely ascendency of American higher education. Chicago: University of Chicago Press.

Marginson, S. (2009). Open source knowledge and university rankings. Thesis Eleven, 96(1), 9-39.

Marginson, S. (2014). University rankings and social science. European Journal of Education, 51(1), 45-59.

Marginson, S. (2017). Do rankings drive better performance? Higher Education International, (89), 6-8.

Muller, J. Z. (2018). The tyranny of metrics. Princeton: Princeton University Press.

Pinheiro, R, \& Geschwind, L. (Eds.). (2018). The responsible university. London: Palgrave.

Sarkozy unveils $€ 35$ bn "big loan" boost for French universities and museums. (2009, December 14). The Guardian. https://www.theguardian.com/world/2009/dec/14/spending-boost-forfrench-universities. Accessed 1 Mar 2019.

Thoenig, J. C., \& Paradeise, C. (2016). Strategic capacity and organisational capabilities: A challenge for universities. Minerva, 54(3), 294-324.

Waltman, L., Wouters, P., \& van Eck, N. J. (2017, May 17). Ten principles for the responsible use of university rankings [Blog post]. Retrieved from https://www.cwts.nl/blog?article=n-r2q274.

Wedlin, L. (2006). Ranking business schools: Forming fields, identities, and boundaries in international business education. Cheltenham: Edward Elgar.

Open Access This chapter is licensed under the terms of the Creative Commons Attribution 4.0 International License (http://creativecommons.org/licenses/by/4.0/), which permits use, sharing, adaptation, distribution and reproduction in any medium or format, as long as you give appropriate credit to the original author(s) and the source, provide a link to the Creative Commons license and indicate if changes were made.

The images or other third party material in this chapter are included in the chapter's Creative Commons license, unless indicated otherwise in a credit line to the material. If material is not included in the chapter's Creative Commons license and your intended use is not permitted by statutory regulation or exceeds the permitted use, you will need to obtain permission directly from the copyright holder.

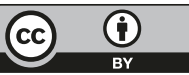

